\title{
Selection of Best Available Wastewater Treatment Technology: Case of Bahir Dar University, Gish Abay Campus, Ethiopia
}

\author{
Yoseph Buat ${ }^{1} \quad$ Atikilt Abebe ${ }^{2}$ \\ 1.School of Civil and Water Resources Engineering, Debre Markos Institute of Technology, Debre Markos, \\ Ethiopia \\ 2.Faculty of Civil and Water Resources Engineering, Bahir Dar Institute of Technology, 26, Bahir Dar, Ethiopia
}

\begin{abstract}
Wastewater treatment in developing countries is not always sustainable due to the application of inappropriate treatment technologies. Construction of best available wastewater treatment technology is a possible solution for the improvement of environmental impact of the available treatment system (septic tank) for Gish Abay Campus, Bahir Dar University. In this study a Multi-Criteria Analysis Decision Making tool is adopted to evaluate different wastewater treatment technologies. A hybrid multiple-criteria decision making model based on the analytic hierarchy process and the technique for order of preference by similarity to ideal solution is proposed as a tool to evaluate and prioritize various wastewater treatment technologies. Wastewater treatment alternatives were evaluated according to economical, technical, environmental and social criteria in which there are ten indicators by equal weight and unequal weight scenarios. Expert responses were used in the selection of wastewater treatment technologies to form different weight matrices. Depending on the priorities of the scenario the alternatives are ranked based on their relative closeness to the ideal solution. The model is finally applied to select best available wastewater treatment technology alternative among three options of sequential batch reactor, up flow anaerobic sludge blanket, and septic tank with horizontal constructed wetland. The result of this study reveal that UASB is best available wastewater treatment alternative. Sensitivity analysis also showed that a very stable ranking with the leading alternative of up flow anaerobic sludge blanket.
\end{abstract}

Keywords: waste treatment alternatives, Multi Criteria Analysis Decision, up flow anaerobic sludge blanket, Analytical Hierarchy Process.

DOI: $10.7176 / \mathrm{CER} / 13-4-02$

Publication date:June $30^{\text {th }} 2021$

\section{INTRODUCTION}

Wastewater is one of today's most important environmental issues that cause severe problems to humans, animals, and the environment caused by improper management and technologies requiring skilled and experienced staff. There is a risk of wastewater treatment technologies due to lack of operators technical and managerial capabilities to perform (El-Naser, 2016).

Selection of best available wastewater treatment technologies that enable sustainable development presents a challenge to national, regional and local policy makers. There is a large gap between municipal wastewater (sewage) generation and available treatment methods. In the future, there will be tremendous efforts and investment by the government to fill this gap through the implementation of best available wastewater treatment technologies. In Ethiopia, the sanitation facility coverage gap remains unacceptably large and collection and emptying mechanisms are one of the challenges. The habit of open field disposal of wastewater is one of the main causes of soil and water contamination and consequently a cause of many communicable diseases. However, streams and rivers passing large cities such as in Addis Ababa are utilized as sewer lines for domestic and industrial wastes (Weldesilassie et al., 2009). Similarly, Wastewater disposal is a serious problem in Bahir Dar town, where most of institutions and industries like Bahir Dar University discharge their effluents without proper treatments. In case of Gish Abay Campus of Bahir Dar University, the wastewater management techniques are localized septic tank system and centralized holding tank with continual desludging. Recent developments in wastewater treatment technologies provide many options for the treatment of wastewater. Many technologies have been developed that employ various treatment processes, both aerobic and anaerobic, highly mechanized to not highly mechanized, including constructed wetland, up flow anaerobic sludge blanket (UASB) reactors, sequential batch reactor (SBR) and stabilization pond, Therefore, there is the need for a decision making tool to aid in the selection of best available wastewater treatment technology for the Campus. This is best done using Multi-criteria decision analysis (MCDA).

\section{MCDA Application for Selection of Wastewater Treatment Alternatives}

MCDA had widespread application to environmental decision-making problems. The applications cover many types of problems in the field, such as environmental planning (Plakas et al., 2016), landfill site selection (Şener et al., 2006), and ranking different contaminated areas according to their need for sediment management; thus conducted a comprehensive review of applications of multi-criteria decision analysis in environmental decision- 
making. The MCDA approach has also been used to address the problem of wastewater treatment alternative selection. Four main criteria were used, and four alternatives were evaluated. Combined AHP with TOPSIS was applied to the selection of optimal wastewater treatment alternatives. These studies show that efforts have been made to address the problem of wastewater treatment alternative selection; however, the complete information available to the decision maker (DM) is not utilized in the decision-making process.

\subsection{Gaps Identified}

Based on the literature survey research gaps were identified and are delineated as follows.

1. Most of methodologies adopted for selection of suitable technology for waste water treatment are on the economic basis but for the sustainable development other factors need to be included such as environmental, social and technical criteria's. This study is aim to include economic, social, technical and environmental as evaluation criteria.

2. Wastewater treatment technology with least life cycle cost may not be suitable for every location hence the ranking of the treatment technology must be done depending on the scenario. This study is aim to rank different treatment technologies based on the basis of two scenarios.

\subsection{Problem Definition}

Great efforts have been made at both global and local levels to encourage and support water supply and sanitation programs in the developing world. Nevertheless, statistical data of 2016/2017 WHO and UNICEF joint monitoring shows that approximately 64 percent of the World's population are living without basic improved sanitation. Although the technologies are available, it has proven difficult to implement them successfully, under the unique local conditions of developing countries. It is the most challenging issue for environmental engineers and decision makers to select and design locally best available wastewater treatment systems to meet the specific needs in developing countries. In Gish Abay campus there is limited amount of land available reserved for accommodate wastewater treatment plant. Thus, there is a need for systematic means to enables the selection of best available wastewater treatment technology with small foot print that suits the campus. In this paper a multiple criteria methodology for selecting best available wastewater technology from a set of feasible alternatives that satisfy local needs.

\section{Methodology}

Available land area for the implementation of the wastewater treatment plant limits the type and the number of the technology that are potentially applicable. There is proposed land in the campus with an area of $11648 \mathrm{~m}^{2}$.

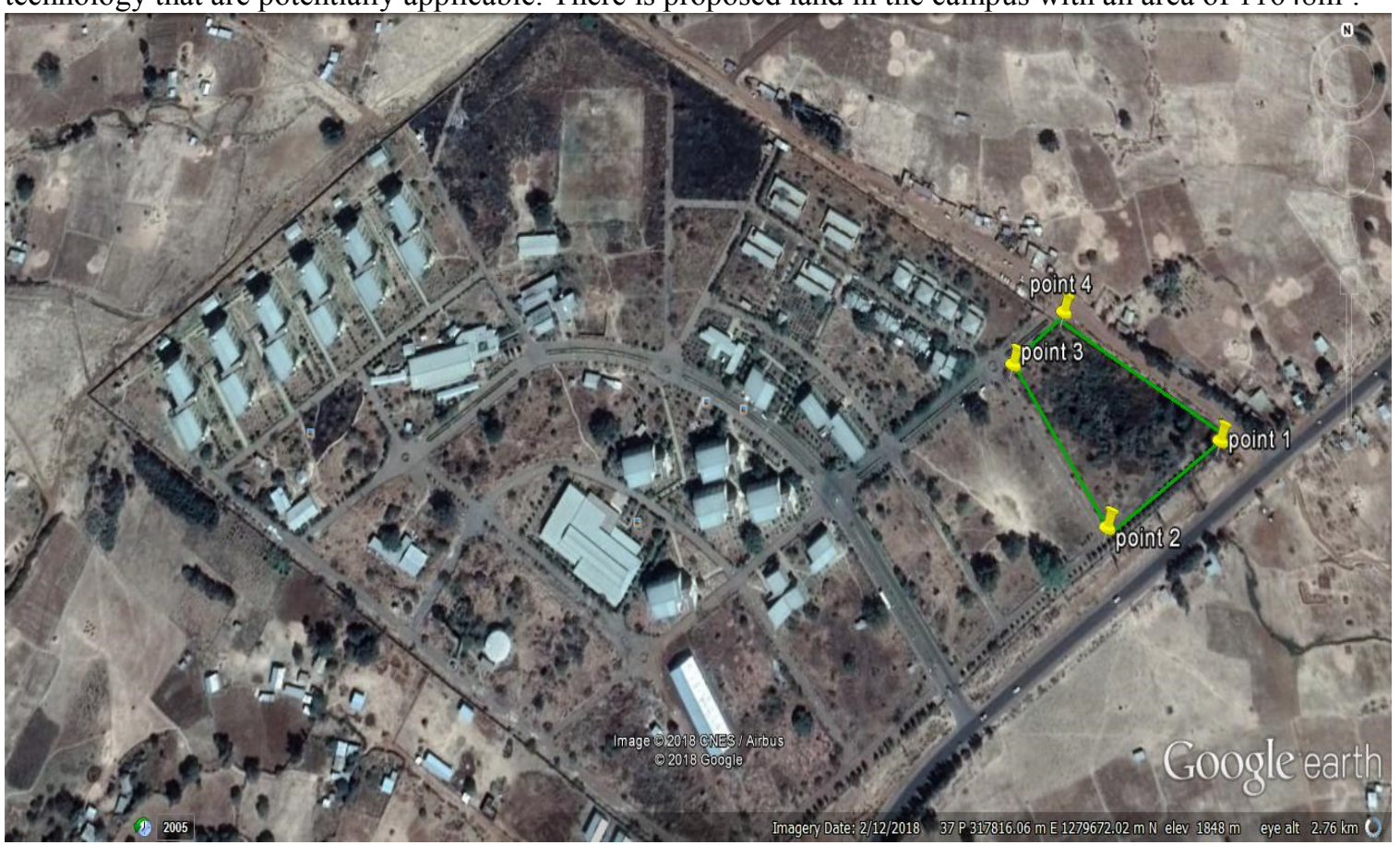

Figure1: Available land in the campus extracted from Google earth

The review of MCDA methods suggests that AHP and TOPSIS are the competing and most widely used methods. AHP is preferred when the information on attributes is available on Saaty's scale, which results in comparison of alternatives in the form of priority, however AHP is not useful when information on attributes is available on a cardinal scale. A major limitation of AHP is that the maximum number of alternatives should be 
kept to less than seven to achieve consistency in the preferences, which makes TOPSIS a better option when there are a large number of alternatives. In this study, hybrid AHP- TOPSIS is preferred for selection of best available wastewater treatment technology. The following subsections describe the criteria and indicators used for the selection of alternative, the articulated scenarios and the application of AHP-TOPSIS for selection of wastewater treatment alternatives.

\subsection{Criteria and Indicators}

The wastewater treatment alternative selection problem involves decision making based on a finite number of alternatives and criteria. Researchers have identified a number of relevant criteria covering technical, economical, societal, and environmental aspects. These criteria can be quantitative or qualitative in nature. In MCDA, there are two ways of measuring preference for a particular alternative under a given attribute, one with ordinal scales and the other with cardinal scales (Pradip P. Kalbar, 2012). With ordinal scales, no numerical properties, such as ratios or intervals, are used; characterization of objects is purely relational, and objects are rank ordered. Intensity of preference is not apparent from ordinal scales.

Ordinal scales can be expressed in terms of numbers or verbal rankings, e.g., 1, 2, 3, 4, etc. or "bad," "good," "excellent," etc. Cardinal scales assign numerical values (numbers, intervals, ratios, etc.) to objects.

\subsubsection{Benefit attributes}

These offer increasing monotonic utility. That is, the greater the attribute value, the more it is preferred. An example is performance efficiency.

\subsubsection{Cost attributes}

These offer decreasing monotonic utility. That is, the greater the attribute value, the less it is preferred. An example is production cost.

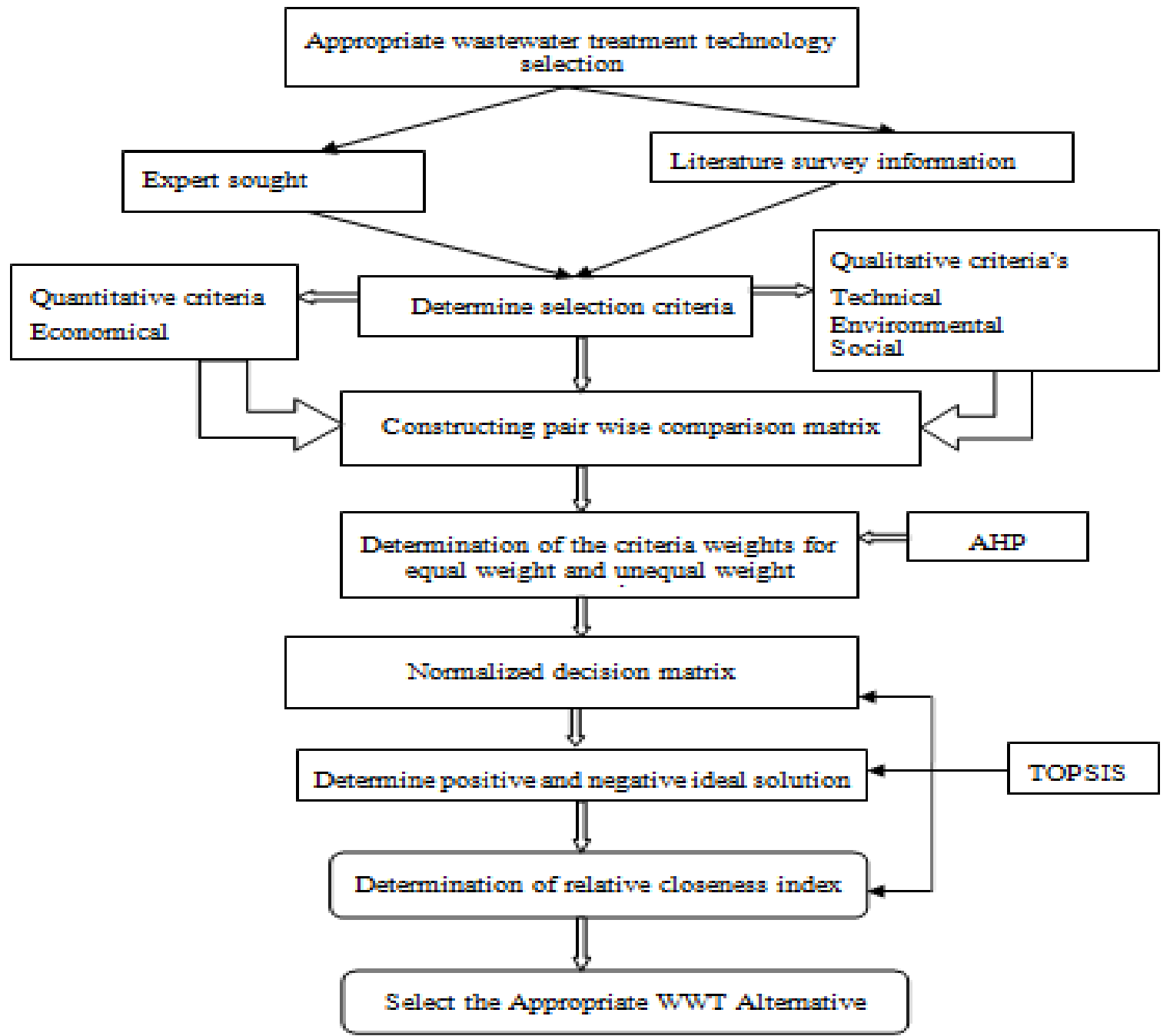

Figure 2 : Flow chart depicting the overall methodology 


\subsection{Estimated Land Requirement of Different Alternatives}

From different literatures of Wastewater treatment technology alternatives investigated; four most commonly used wastewater treatment technology alternatives in developing countries are pre selected and farter evaluated. These technologies are: Sequential Batch Reactor (SBR), Waste Stabilization Ponds (WSP), Septic Tank plus horizontal flow Constructed Wetlands (ST+HFCW) and Up-flow Anaerobic Sludge Blanket (UASB) were evaluated in this study.

Table 1: Estimated Land Requirement of different wastewater alternatives

\begin{tabular}{|l|l|}
\hline Wastewater treatment technology & Required land area $\left(\mathbf{m}^{2} / \mathbf{m}^{3} / \boldsymbol{d}\right)$ \\
\hline SBR & 1.33 \\
WSP & 21.67 \\
ST+HFCW & 4.9 \\
UASB & 2.7 \\
\hline
\end{tabular}

Source: (Massoud et al., 2009), (Tchobanoglous et al., 1991)

\subsection{Development of Main Criteria and Indicators}

This study shows different factors to select appropriate wastewater treatment technology in the campus. Technical, social, economic and environmental concerns are useful to develop a set of criteria and indicators useful for evaluating appropriate wastewater treatment technology alternatives. Factors that must be considered in the selection of wastewater treatment technologies have been widely researched into and as a result a wide body of literature exist that list these important factors.

Appropriate treatment technologies being simple treatment processes of proven technology, capable of providing any required effluent quality (technical criteria) at low investment, operation and maintenance costs (economic criteria) with minimal impact on the environment (environmental criteria) and acceptable to users (socio-cultural criteria) are required to overcome the challenges of wastewater treatment and management.

The developing process of criteria and indicators involves the following steps:

1.Identify the ideas or conceptual variables from the appropriate wastewater treatment technology concept; based on literature review about the definition and understanding of appropriate treatment technology, an initial set of criteria for the assessment of the treatment technologies have been identified.

2. Identify the dimension of interests in each conceptual variable;

3. Transformation of sub-criteria into indicators for data collection and measurements. i.e. operational variables for measurements.

4. Organize all relevant variables into three hierarchical elements; namely, criteria, sub-criteria, and indicators; Criteria's: which are broadly defined, refer to the main ideas or concepts of appropriate wastewater treatment systems for developing countries.

Sub-Criteria: demonstrate the dimension of interests in each criterion need to be assessed; however, they still have conceptual characteristic.

Indicators: are the components or variables that indicate the state or conditions required by each sub-criterion. These are real information that can be measured in different ways.

\subsubsection{Quantification of Qualitative Indicators}

There are four types of scales used to assign scores or values to attribute: nominal, cardinal, interval and ratio. Cardinal scale is used to transform qualitative indicator and to measure differences from some point arbitrary (Odu and Charles-Owaba, 2013).

Parameters are qualitative in nature and to quantify qualitative indicators, a cardinal scale of 1 and 10 . In this study indicators of technical, environmental and social criteria's considered as qualitative those described by cardinal scale.

\subsubsection{Economical Criteria}

Economic criteria are one of the key factors acting as a constraint to the application of wastewater treatment technologies and practices in developing countries. It addresses the potential financial obligation in terms of the capital, operation and maintenance cost.

Economic criteria expressed as a net present value (NPV) of indicators quantified as the present value method determine by CLARA Simplified Planning Tool (SPT) Software tool which allows the comparison of different water and sanitation systems based on their

net present value (Lechner et al., 2014). This software tool is based on numbers of simplifying assumptions, which allow the planner to use the SPT with the limited amount of data available at the planning stage of a project. Ethiopia net Interest Rate - actual data and calendar of releases was last updated of 2018 is $7 \%$ as stated by national bank of Ethiopia.

Net present value (NPV): NPV of a time series of cash flows, both incoming and outgoing, is defined as the sum of the present values (PVs) of the individual cash flows of the same entity. NPV is a central tool in discounted cash flow analysis and is a standard method for using the time value of money to appraise long-term projects. Each 
cash inflow/outflow is discounted back to its present value. Then they are summed. The net present value NPV is calculated by:

Table 2: Indicators of economic criteria

\begin{tabular}{|l|c|}
\hline Indicator & Unit of quantification \\
\hline $\begin{array}{l}\text { Capital cost } \\
\text { Operation and maintenance co } \\
\text { Rehabilitation cost }\end{array}$ & Total Cost in $€$ \\
\hline
\end{tabular}

CLARA-SPT was applied to compare the life time cost of the proposed wastewater treatment technologies.WWT technologies are planned to manage the domestic wastewater generated from Gish Abay campus of Bahir Dar University. Input parameters for different WWT technologies are population equivalent served; cost function and life spans in year.

\subsubsection{Technical criteria's}

1. Performance

For the identification of an appropriate wastewater treatment technology for the study area, this study takes into consideration the core purpose of a treatment plant, that is the removal of water quality contaminants. Contaminants in wastewater are numerous but since the focus is on municipal wastewater treatment, the conventional water quality constituents associated with wastewater treatment namely: $\mathrm{BOD}_{5}, \mathrm{COD}$ and TDS were quantified by adopting values considered to be typical removal efficiencies by technical literature of the different wastewater treatment technologies.

Table 3: Indicators to evaluate performance

\begin{tabular}{ll}
\hline Indicators & Unit quantification \\
\hline $\mathrm{BOD}_{5}$ & \\
$\mathrm{COD}$ & Percent of removal \\
$\mathrm{TDS}$ & \\
\hline
\end{tabular}

2. Reliability: refers to the possibility of different failures and the impact of failures upon effluent quality.

Table 4: Indicators to evaluate Reliability

\begin{tabular}{|c|c|}
\hline $\begin{array}{l}\text { Indicator } \\
\text { Reliability }\end{array}$ & $\begin{array}{l}\text { Unit of quantification } \\
1-10 \text { (cardinal scale) }\end{array}$ \\
\hline $\begin{array}{l}\text { 2.3.4 Social criteria } \\
\text { In order to select the most appropriate WWT } \\
\text { the study area must be evaluated. } \\
\text { 1. Acceptability by users: The degree of acce } \\
\text { 2. Healthy Effects on surrounding community } \\
\text { technology on people living nearby. } \\
\text { Table 5: Indicators of social criteria }\end{array}$ & $\begin{array}{l}\text { the impact of each technology on the social welfare of } \\
\text { ach treatment technology must be evaluated. } \\
\text { riterion represents the health impacts of each treatment }\end{array}$ \\
\hline $\begin{array}{l}\text { Indicator } \\
\text { Acceptability by users } \\
\text { Healthy Effects on surrounding community }\end{array}$ & $\begin{array}{l}\text { Unit of quantification } \\
1-10 \text { (Cardinal scale) }\end{array}$ \\
\hline
\end{tabular}

Description: $1=$ very low, $5=$ medium and $10=$ very high 
Table 6: Set of criteria and indicators for analysis

\begin{tabular}{|c|c|c|}
\hline \multirow{4}{*}{$\begin{array}{l}\text { Criteria } \\
\text { economical }(\mathrm{c} 1)\end{array}$} & Indicator & objective \\
\hline & capital $\operatorname{cost}\left(\mathrm{i}_{1}\right)$ & $\begin{array}{l}\text { Determines the costs for civil and electro } \\
\text { mechanical work to implement the whole system. }\end{array}$ \\
\hline & $\begin{array}{l}\text { operation and maintenance } \\
\operatorname{cost}\left(\mathrm{i}_{2}\right)\end{array}$ & $\begin{array}{l}\text { Determine the maintenance, personnel, and energy } \\
\text { and sludge disposal expenses. }\end{array}$ \\
\hline & rehabilitation cost $\left(\mathrm{i}_{3}\right)$ & \\
\hline \multirow[t]{3}{*}{ technical $\left(c_{2}\right)$} & performance $\left(\mathrm{i}_{4}\right)$ & $\begin{array}{l}\text { Determines the extent of constituent removal } \\
\text { (particulate BOD and suspended solids) in the } \\
\text { wastewater. }\end{array}$ \\
\hline & reliability $\left(\mathrm{i}_{5}\right)$ & $\begin{array}{l}\text { evaluate the ability of response to hydraulic and } \\
\text { organic loading }\end{array}$ \\
\hline & complexity $\left(\mathrm{i}_{6}\right)$ & $\begin{array}{l}\text { determine the special needs of system operation } \\
\text { and maintenance }\end{array}$ \\
\hline \multirow[t]{2}{*}{ environmental(c3) } & noise generation $\left(\mathrm{i}_{7}\right)$ & $\begin{array}{l}\text { determine the environmental impact due to noise } \\
\text { pollution due to moving parts }\end{array}$ \\
\hline & Odour production potential $\left(\mathrm{i}_{8}\right)$ & $\begin{array}{l}\text { determine the environmental impact due to odour } \\
\text { generation }\end{array}$ \\
\hline social (c4) & $\begin{array}{l}\text { acceptability by users }\left(i_{9}\right) \\
\text { healthy effects on surrounding } \\
\text { community }\left(i_{10}\right)\end{array}$ & $\begin{array}{l}\text { to actively involve the key stakeholders } \\
\text { reducing mortality due to diharial diseases } \\
\text { and other type of diseases }\end{array}$ \\
\hline
\end{tabular}

\subsection{Application of MCDM for Appropriate WWT Technology Selection}

The problem is to choose the most appropriate treatment system for the specific area or rank the alternatives according to how well they will perform. But in order to achieve this, the selection or ranking procedure must take into account not only the technical capacities of the treatment alternatives but also the environmental, social and economic concerns. This makes it a multi-criteria decision making problem which can better be resolved by a Multi-criteria Decision Making method. A review of MADM methods and the nature of this decision problem suggest that AHP and Technique for Order Preference by Similarity to Ideal Solution (TOPSIS) are the most appropriate methods to apply.AHP, as a complementary method, provides the input weights for the TOPSIS procedure. Therefore, a questionnaire was designed based on AHP and TOPSIS principle.

The AHP method can be expressed in following steps:

(1) Construct a Comparison Matrix

A pair wise comparison matrix of criteria is constructed using a scale of relative importance.

After the calculation of relative importance, the pair wise comparison matrix is converted into a single-value comparison matrix. The quantified judgments on pairs of criteria $A i$ and $A j$ are represented by $n \times n$ single-value comparison matrix.

According to saaty scale, the available values for the pair-wise comparisons are:

$$
\left\{9,8,7,6,5,4,3,2,1, \frac{1}{2}, \frac{1}{3}, \frac{1}{4}, \frac{1}{5}, \frac{1}{6}, \frac{1}{7}, \frac{1}{8}, \frac{1}{9}\right\}
$$

(2). calculate the importance degree of each element

The weighting vector of a specific element $k$ can be calculated through Equation (Sipahi and Timor, 2010)

(3) Consistency Test

The consistency of pair wise comparisons has to be checked before achieving a convincing result. The comparisons will be considered reasonable only if the consistency ratio is equal to or less than 0.10 . An approximation of the ratio can be obtained using the algorithm described in Equation.

Table 7: Average random index value

\begin{tabular}{lllllllllll}
\hline $\mathrm{N}$ & 1 & 2 & 3 & 4 & 5 & 6 & 7 & 8 & 9 & 10 \\
$\mathrm{RI}$ & 0 & 0 & 0.52 & 0.89 & 1.11 & 1.25 & 1.35 & 1.4 & 1.45 & 1.49 \\
\hline
\end{tabular}

The wastewater treatment alternatives were evaluated against objectives using the identified evaluation criteria, weightings of criteria and indicators by running the Microsoft Excel® spreadsheet, which use the AHP of MCDA algorithm. Therefore, in order to ranking or prioritize the alternative, the local weight of each criteria and indicators $(\mathrm{C} \& \mathrm{I})$ and the local weight of alternatives with respect to each indicator are combine according to AHP as follows:

In TOPSIS methods for ranking the finite set of alternatives is on the basis of multiple attributes.

Benefit attributes offer increasing monotonic utility which is the greater the attribute value, the more it is preferred where as cost attributes offer decreasing monotonic utility which is, the greater the attribute value, the less it is preferred.

TOPSIS is used for ranking the technologies based on the similarities to positive ideal solution. For cost 
attribute, lowest score of any alternative is called positive ideal solution and highest score is called negative ideal solution. For benefit attributes say reliability, highest score is called positive ideal solution and lowest score is called negative ideal solution. This method is based on the fact that the alternative will have better rank (or preferred first) which is close to the separation measure of positive ideal solution ( $\left.\mathrm{Di}^{+}\right)$and farthest to the separation measure of negative ideal solution ( $\mathrm{Di}^{-}$). For ranking the alternatives based on the values of separation measure of positive ideal solution $\left(\mathrm{Di}^{+}\right)$and separation measure of negative ideal solution ( $\mathrm{Di}^{-}$) TOPSIS consider both the distance simultaneously. Hence for considering both the distances simultaneously, ranking is done based on the value of relative closeness index $(\mathrm{R} * \mathrm{i})$. Alternative having least value of relative closeness index $(\mathrm{R} * \mathrm{i})$ will be preferred first. To calculate separation measures $\left(\mathrm{Di}^{+}\right.$and $\mathrm{Di}^{-}$), weighted normalized rating aij(of $j$ th indicator for $i^{\text {th }}$ alternative) is calculated by using normalized rating (rij) and normalized rating has been calculated by vector normalization of score matrix of alternatives.

Based on the methodology discussed above Analytic Hierarchy Process (AHP) and Technique for Order Preference by Similarity to Ideal Solution (TOPSIS) methods are designed. In this respect, the aim of using AHP is to analyze the structure of the appropriate wastewater treatment alternative selection problem and obtain weights of the selected indicators. Then, TOPSIS technique is used to calculate the alternatives' ratings.

AS widely studied by different researchers and practitioners there are seven steps for the classical TOPSIS method:

1. Create an evaluation matrix consisting of $m$ alternative and $n$ attributes, with the intersection of each alternative and attributes given as $\mathrm{x}_{\mathrm{ij}}$ with matrix $\left(\mathrm{x}_{\mathrm{ij}}\right)_{\mathrm{mxn}}$

2. Normalize the matrix $\left(\mathrm{x}_{\mathrm{ij}}\right)_{\mathrm{mxn}}$ to form the matrix $\mathrm{R}=\left(\mathrm{r}_{\mathrm{ij}}\right)_{\mathrm{mxn}}$ using normalization method.

3. Calculate the weighted normalized decision matrix

4. Determine the negative ideal solution (ideal worst alternative) $\mathrm{A}^{-}$and the positive ideal solution (ideal best alternative) $\mathrm{A}^{+}$.

5. Calculate the distance between target alternative $\mathrm{i}$ and the worst condition $\mathrm{A}^{-}$and

6. Calculate the similarity to the worst condition

7. Ranking the alternative according to $R^{*}$

\subsection{Decision-Making Scenarios}

In this study the selection of best available wastewater alternatives based on two scenarios those reflects a holistic approach.

\subsubsection{Equal Weight Scenario}

In this study to represent equal weight scenario a hybrid AHP-TOPSIS were used; where decision makers have no reason to make some indicators more important than the others. All weights are made equal to indicate equal importance for all indicators. Such a uniform distribution is being applied for designed AHP-TOPSIS technique.

\subsubsection{Unequal Weight Scenario}

Under this scenario the weights of importance of the indicators for determining the most appropriate treatment alternative for a campus are unequal and they are apportioned by the experts to reflect the treatment priorities. To represent such an instance, AHP-TOPSIS method is adopted to determine the weights of indicators in this scenario. AHP-TOPSIS application in the context of this study is based on the fact that, the decision matrix possesses a certain amount of information that can be assessed to elicit the weights of importance of indicators.

\section{RESULTS AND DISCUSSION}

\subsection{Land Requirement}

The size and availability of land are the primary criteria determining the choice of wastewater treatment process. In the context of this study, minimum land requirement is seen as a benefit because of limited land area for wastewater treatment plant in the campus.

The available land size with respect to quantity of wastewater in the campus is $14.6 \mathbf{~ m}^{2} / \mathbf{m}^{3} / \mathbf{d}$.

Land requirement of wastewater treatment plants indicates that there is a strong correlation between the land requirement and wastewater flow. 


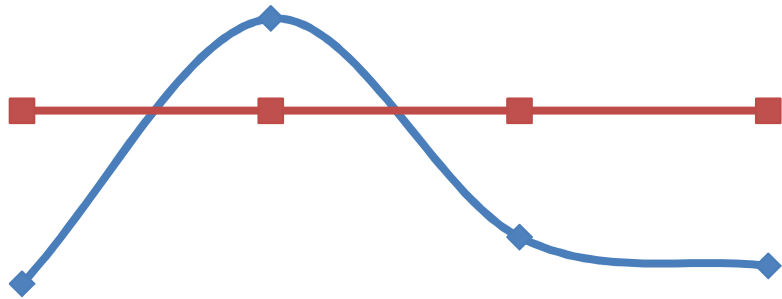

Required land area $\left(\mathrm{m}^{\wedge} 2 / \mathrm{m}^{\wedge} 3 / \mathrm{d}\right)$

$\rightarrow-$ Available land area $\left(\mathrm{m}^{\wedge} 2 / \mathrm{m}^{\wedge} 3 / \mathrm{d}\right)$

Alternatives

Figure 3 : Land requirement of different WWTT Alternatives

In this study, wastewater treatment alternatives are ranked for two scenarios case. Table shows the relative distance matrix (score) for each of the three alternatives, with their respective ranks under each scenario. For the "no scenario" case, for which all indicators are assumed to have equal weights, the alternatives have almost equal scores, resulting in difficulty in selection of the most appropriate alternative. Equal scores suggest that all of the alternatives are equidistant from the ideal and non-ideal solutions, which can be clearly conceptualized from Fig. 2. The "no scenario" radar plot in Fig. 2 shows that the PIS and NIS cover opposite areas. The alternative that is most preferred should cover the maximum area under the PIS, i.e., it should be the alternative with the greatest similarity to the

\subsection{CLARA-SPT Cost Estimation Result of WWTT Alternatives}

Input data's: Period consideration $=25$ years

Total cost of WWTT alternative is the sum of initial investment cost and recurrent expenses (i.e. O\&M and reinvestment costs) incurred over the planning period. Residual value is the remaining asset value of a system at the end of the planning period, which is expressed as a negative value of costs (Ketema et al., 2014). The initial investment cost and O\&M cost of UASB is least as compared with other alternatives as shown in figure 4.

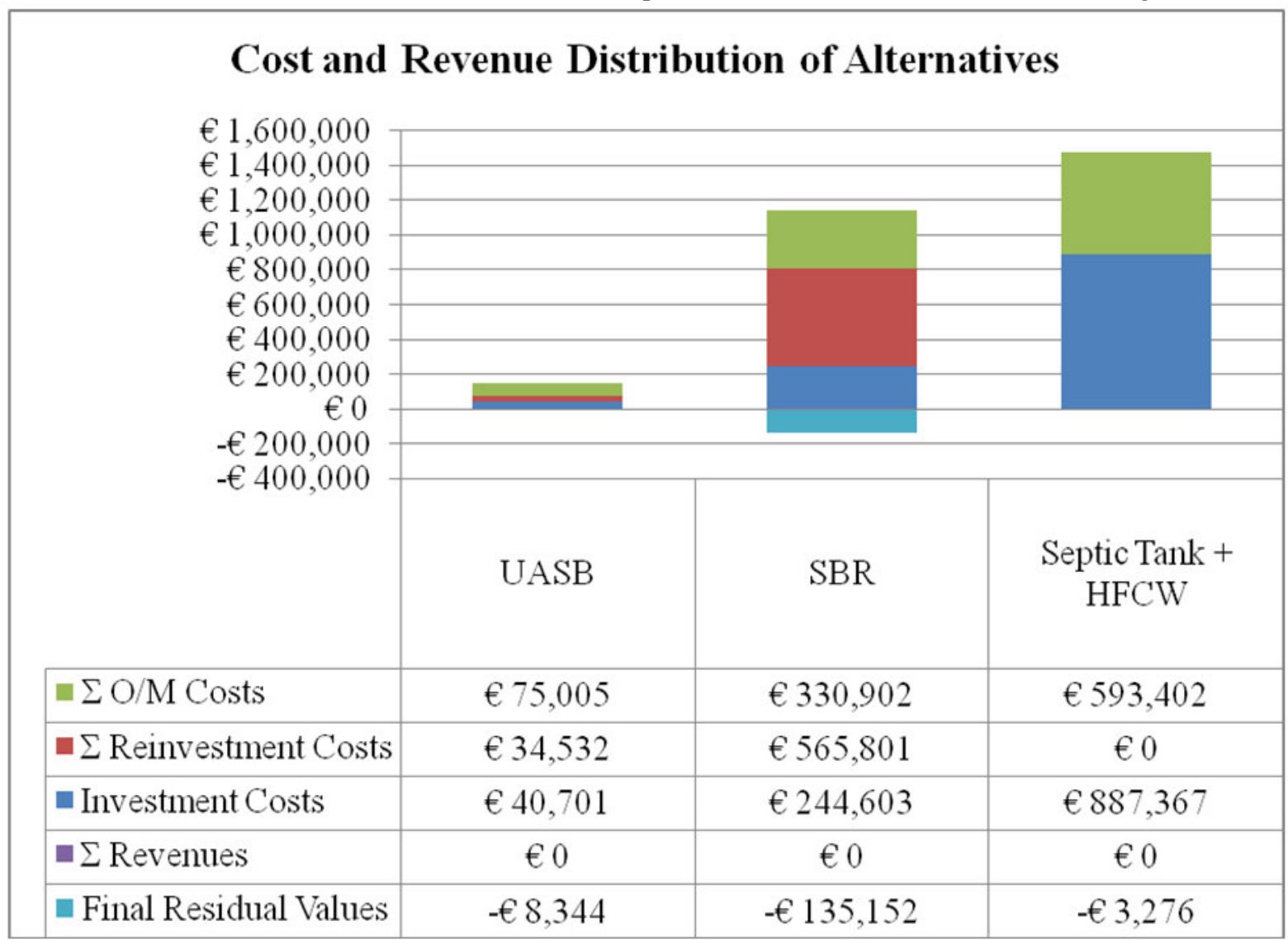

Figure 4: Life time cost development of the three wastewater alternatives over 25 years 
UASB has least cost with CLARA-SPT software analysis. It was expected that these economic indicators would have been judged as being important in selection of appropriate wastewater treatment technology.

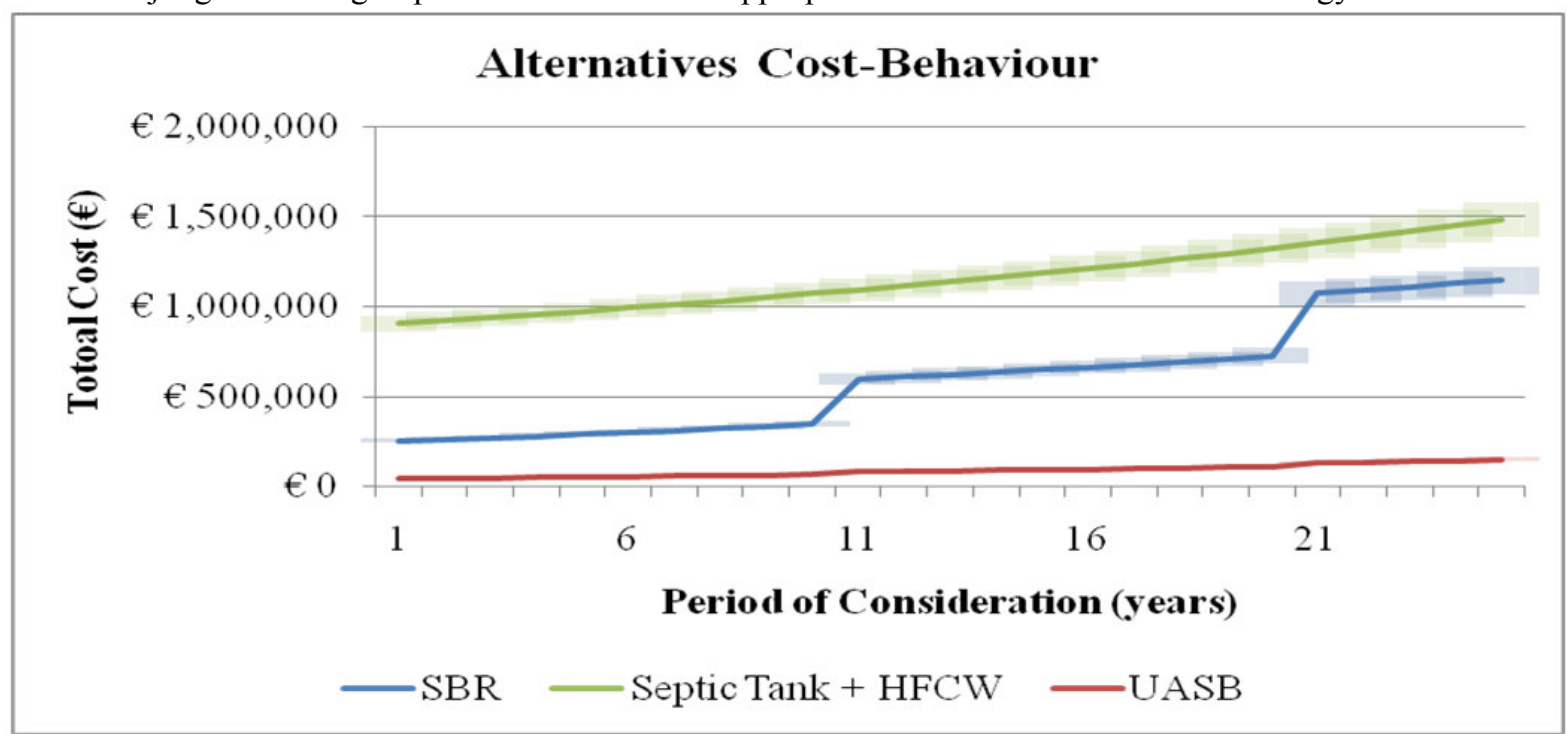

Figure 5: Total cost development of the three wastewater treatment alternatives over 25 years

As per framework decided for the selection of appropriate wastewater technology; Data analysis has been done for the calculation of cost (figure 5) and other qualitative parameters. The quantitative scores thus assigned listed in Table 8. In this study scores of qualitative parameters has been taken on the cardinal scale of 1-10 (1for worst condition and 10 for best condition).

Table 8: Normalized rating (rij) of three alternatives (Equal weight scenario)

\begin{tabular}{lccc}
\hline Indicators & SBR & UASB & Septic Tank + HFCW \\
Capital cost $(€)$ & 0.2655 & 0.0442 & 0.9631 \\
Operation and maintenance cost $(€)$ & 0.4841 & 0.1097 & 0.8681 \\
Rehabilitation cost $(€)$ & 0.9981 & 0.0609 & 0.0000 \\
COD removal efficiency (\%) & 0.6362 & 0.4865 & 0.5988 \\
BOD removal efficiency (\%) & 0.6286 & 0.4944 & 0.6004 \\
TSS removal efficiency (\%) & 0.5967 & 0.4972 & 0.6298 \\
Reliability & 0.6623 & 0.5298 & 0.5298 \\
Complexity & 0.5270 & 0.8433 & 0.1054 \\
Smell Impact & 0.5523 & 0.0921 & 0.8285 \\
Noise generation & 0.5774 & 0.8083 & 0.1155 \\
Acceptability by users & 0.3885 & 0.8742 & 0.2914 \\
Healthy Effects on surrounding community & 0.5883 & 0.1961 & 0.7845 \\
\hline
\end{tabular}

Table 9: Normalized rating (rij) of three alternatives (Un-Equal weight scenario)

\begin{tabular}{llll}
\hline Indicators & SBR & UASB & Septic Tank + HFCW \\
Capital cost $(€)$ & 0.2655 & 0.0442 & 0.9631 \\
Operation and maintenance cost $(€)$ & 0.4841 & 0.1097 & 0.8681 \\
Rehabilitation cost $(€)$ & 0.9981 & 0.0609 & 0 \\
COD removal efficiency (\%) & 0.6362 & 0.4865 & 0.5988 \\
BOD removal efficiency (\%) & 0.6286 & 0.4944 & 0.6004 \\
TSS removal efficiency (\%) & 0.5967 & 0.4972 & 0.6298 \\
Reliability & 0.6140 & 0.5581 & 0.5581 \\
Complexity & 0.5270 & 0.8433 & 0.1054 \\
Smell Impact & 0.5523 & 0.0921 & 0.8285 \\
Noise generation & 0.5774 & 0.8083 & 0.1155 \\
Acceptability by users & 0.3885 & 0.8742 & 0.2914 \\
Healthy Effects on surrounding community & 0.5883 & 0.1961 & 0.7845 \\
\hline
\end{tabular}


Table 10: Relative closeness index for three alternatives

\begin{tabular}{lllll} 
& ALTERNATIVES & SBR & UASB & ST +HF CW \\
\hline Scenario 1 & Relative Closeness Index $(\mathrm{R} * \mathrm{i})$ & 0.477783 & 0.590242 & 0.489374 \\
& Rank & 3 & 1 & 2 \\
Scenario 2 & Relative closeness index $(\mathrm{R} * \mathrm{i})$ & 0.245 & 0.273 & 0.120 \\
& Rank & 2 & 1 & 3
\end{tabular}

The overall result of the analysis for both scenarios (equal weight and unequal weight) shows that UASB holds first rank.

\subsection{Sensitivity Analysis}

Sensitivity analysis is an essential technique used in MCA to examine the feasibility and reliability of treatment alternative with regards to sub-criteria priorities. Thus, it is possible to explain the different preferences that the analysis could make with respect to the criteria applied, and how they impact the results. Small changes in relative weights would have major changes in the final ranking of alternatives. Such weights are usually based on highly individual decisions and therefore, ranking stability under varying weights should be tested. In this study sensitivity analysis was carried out by changing the relative weight of the criteria one at a time and taking a record of the changes in the rank results. Analysis is performed to analyze the combined AHP and TOPSIS methodology proposed in this study. For this reason, the criteria weights obtained from AHP are exchanged between two criteria while the others are constant.

Table 11: Conditions for sensitivity analysis

\begin{tabular}{|c|c|c|c|c|c|c|c|c|c|c|c|c|c|}
\hline Indicators & Main & 1 & 2 & 3 & 4 & 5 & 6 & 7 & 8 & 9 & 10 & 11 & Equal \\
\hline Capital cost $(€)$ & 0.056 & 0.106 & 0.03 & 0.137 & 0.137 & 0.137 & 0.256 & 0.306 & 0.089 & 0.191 & 0.242 & 0.081 & 0.1 \\
\hline $\begin{array}{l}\text { Operation and maintenance } \\
\text { cost }(€)\end{array}$ & 0.106 & 0.0558 & 0.106 & 0.106 & 0.106 & 0.106 & 0.106 & 0.106 & 0.106 & 0.106 & 0.106 & 0.106 & 0.1 \\
\hline Rehabilitation Cost (€) & 0.03 & 0.03 & 0.0558 & 0.03 & 0.03 & 0.03 & 0.03 & 0.03 & 0.03 & 0.03 & 0.03 & 0.03 & 0.1 \\
\hline COD removal efficiency (\%) & 0.137 & 0.137 & 0.137 & 0.0558 & 0.137 & 0.137 & 0.137 & 0.137 & 0.137 & 0.137 & 0.137 & 0.137 & 0.033 \\
\hline BOD removal efficiency (\%) & 0.137 & 0.137 & 0.137 & 0.137 & 0.0558 & 0.137 & 0.137 & 0.137 & 0.137 & 0.137 & 0.137 & 0.137 & 0.033 \\
\hline TSS removal efficiency (\%) & 0.137 & 0.137 & 0.137 & 0.137 & 0.137 & 0.0558 & 0.137 & 0.137 & 0.137 & 0.137 & 0.137 & 0.137 & 0.033 \\
\hline Reliability & 0.256 & 0.256 & 0.256 & 0.256 & 0.256 & 0.256 & 0.0558 & 0.256 & 0.256 & 0.256 & 0.256 & 0.256 & 0.1 \\
\hline Complexity & 0.306 & 0.306 & 0.306 & 0.306 & 0.306 & 0.306 & 0.306 & 0.0558 & 0.306 & 0.306 & 0.306 & 0.306 & 0.1 \\
\hline Smell Impact & 0.089 & 0.089 & 0.089 & 0.089 & 0.089 & 0.089 & 0.089 & 0.089 & 0.0558 & 0.089 & 0.089 & 0.089 & 0.1 \\
\hline Noise generation & 0.191 & 0.191 & 0.191 & 0.191 & 0.191 & 0.191 & 0.191 & 0.191 & 0.191 & 0.0558 & 0.191 & 0.191 & 0.1 \\
\hline Acceptability by users & 0.242 & 0.242 & 0.242 & 0.242 & 0.242 & 0.242 & 0.242 & 0.242 & 0.242 & 0.242 & 0.0558 & 0.242 & 0.1 \\
\hline $\begin{array}{l}\text { Healthy Effects on } \\
\text { surrounding community }\end{array}$ & 0.081 & 0.081 & 0.081 & 0.081 & 0.081 & 0.081 & 0.081 & 0.081 & 0.081 & 0.081 & 0.081 & 0.0558 & 0.1 \\
\hline
\end{tabular}




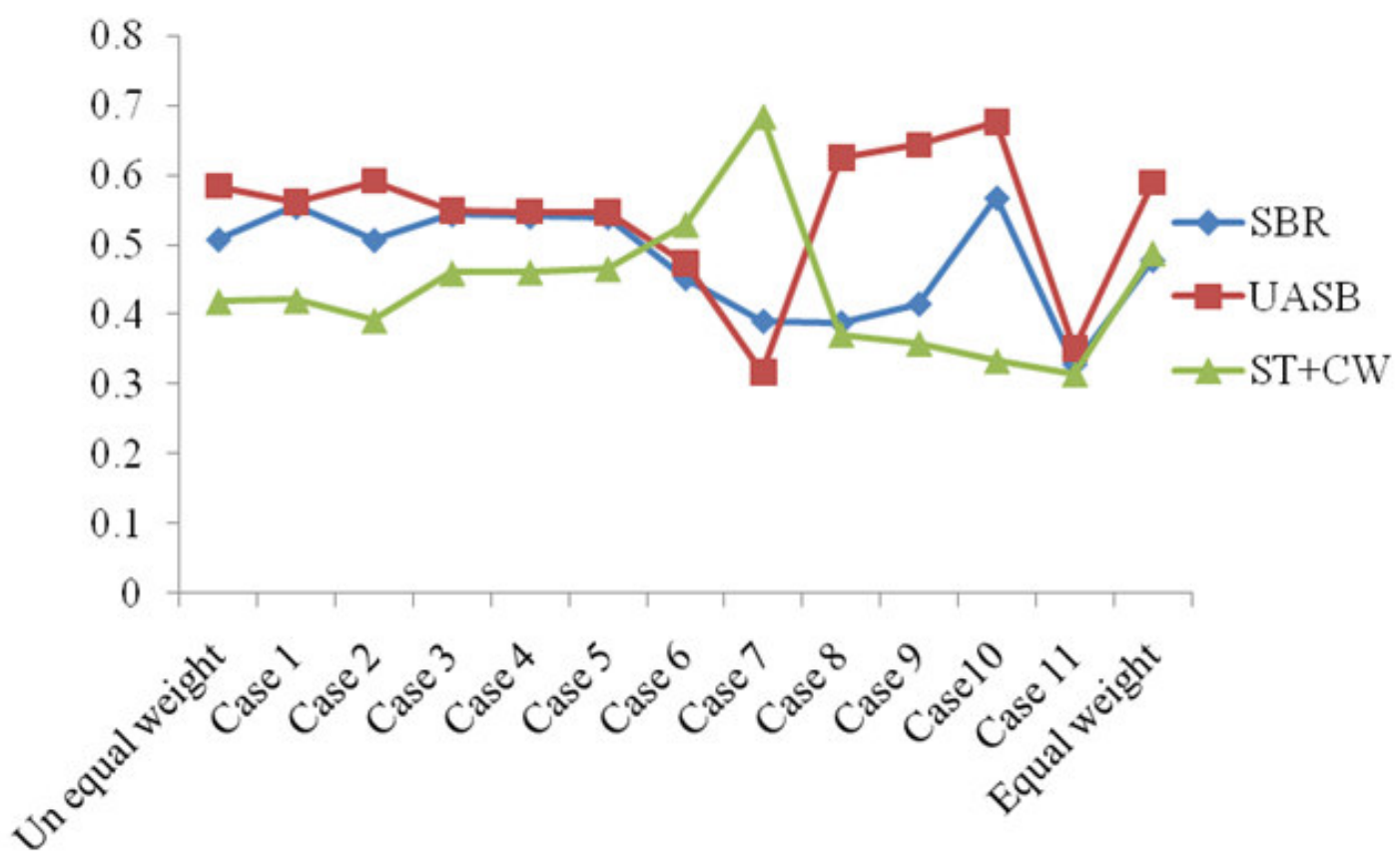

Figure 0.10: Sensitivity analysis under different indicators weight

From Table 11 and Fig 4.10, it can be seen that the first case describes the unequal weight results of the hybrid (combined) methodology. Also, UASB has the highest score in all cases except in case 7.

The final result that can be drawn from this sensitivity analysis is that the appropriateness of UASB for Gish Abay campus is robust as it remains unchanged irrespective of the weight variation of the indicators except reliability. This result shows that reliability is the most sensitive indicator in wastewater treatment technology selection.

\section{Conclusion}

Gish Abay Campus of Bahir Dar University currently lacks improved wastewater treatment facility. As a result this study focuses on selection of an appropriate wastewater treatment technology using combined AHP and TOPSIS decision model as multi criteria decision making analysis tool. To achieve this goal identification and analysis of different criteria's and their indicators were performed. The AHP method was used to calculate the weights of indicators, and the TOPSIS technique, which is based on the relative distance of alternatives from the positive and negative ideal solutions simultaneously, was employed to prioritize the appropriate treatment technology.

The result of this hybrid AHP-TOPSIS model showed that UASB is identified as an appropriate wastewater treatment technology for both equal weight and unequal weight scenarios among the three wastewater treatment technologies alternative considered in the study.

The sensitivity analysis indicates that ranking of alternative were influenced by reliability indicators. Finally after implementing this appropriate treatment technology the status of wastewater management and sanitation of the campus will improve as per the Ethiopian environmental standard.

\section{REFERENCES}

Abdullah L. (2015) Developing decision on suitable wastewater treatment technology using fuzzy simple additive weighting. International Journal of Engineering and Technology 7.

Afshar A, Mariño MA, Saadatpour M, et al. (2011) Fuzzy TOPSIS multi-criteria decision analysis applied to Karun reservoirs system. Water resources management 25: 545-563.

Agudelo C, Mels A and Braadbaart O. (2007) Multi-criteria framework for the selection of urban sanitation systems. Proceedings of the 2 nd SWITCH Scientific Meeting. 25-29.

Amenu D. (2014) Characterization of wastewater and evaluation of the effectiveness of the wastewater treatement systems. World Journal of Life Sciences Research 1: 1-11.

ANRSWRDB. (2012) Amhara Water Resources Development Bureau Water Supply Core Process

Water Supply Design Guideline.

Birol E and Das S. (2010) Estimating the value of improved wastewater treatment: The case of River Ganga, India. Journal of Environmental Management 91: 2163-2171.

Chauhan A and Singh A. (2016) A hybrid multi-criteria decision making method approach for selecting a 
sustainable location of healthcare waste disposal facility. Journal of cleaner production 139: 1001-1010.

Chen X, Xu Z, Yao L, et al. (2018) Processing Technology Selection for Municipal Sewage Treatment Based on a Multi-Objective Decision Model under Uncertainty. International journal of environmental research and public health 15: 448.

Coulibaly SL, Sangaré D, Akpo SK, et al. (2016) Assessment of Wastewater Management and Health Impacts in African Secondary Cities: Case of Dimbokro (Côte D'Ivoire). Journal of Geoscience and Environment Protection 4: 15.

Curiel-Esparza J, Cuenca-Ruiz MA, Martin-Utrillas M, et al. (2014) Selecting a sustainable disinfection technique for wastewater reuse projects. Water 6: 2732-2747.

Deepa K and Krishnaveni M. (2012) Suitable site selection of decentralised treatment plants using multicriteria approach in GIS. Journal of Geographic Information System 4: 254.

Eaton AD, Clesceri LS, Greenberg AE, et al. (2005) Standard methods for the examination of water and wastewater. American public health association 1015: 49-51.

El-Naser DH. (2016) Decentralized wastewater managment policy.

Engin GO and Demir I. (2006) Cost analysis of alternative methods for wastewater handling in small communities. Journal of Environmental Management 79: 357-363.

Feenstra S, Hussain R and van der Hoek W. (2000) Health risks of irrigation with untreated urban wastewater in the southern Punjab, Pakistan. International Water Management Institute Lahore.

Fenta BA. (2017) Waste management in the case of Bahir Dar City near Lake Tana shore in Northwestern Ethiopia: A review. African Journal of Environmental Science and Technology 11: 393-412.

Flores CC, Özerol G and Bressers H. (2017) "Governance restricts": A contextual assessment of the wastewater treatment policy in the Guadalupe River Basin, Mexico. Utilities Policy 47: 29-40.

Haddis A, De Geyter A, Smets I, et al. (2014) Wastewater management in Ethiopian higher learning institutions: functionality, sustainability and policy context. Journal of Environmental Planning and Management 57: 369383.

Hanine M, Boutkhoum O, Tikniouine A, et al. (2016) Application of an integrated multi-criteria decision making AHP-TOPSIS methodology for ETL software selection. SpringerPlus 5: 263.

Hasanloo S, Karim E, Mehregan M, et al. (2013) Evaluating performance of companies by new management tools. European Online Journal of Natural and Social Sciences: Proceedings 2: pp. 165-169.

Jorge Curiel-Esparza 1, Marco A. Cuenca-Ruiz 2, Manuel Martin-Utrillas 1 and 3 aJC-P. (2014) Selecting a Sustainable Disinfection Technique for Wastewater Reuse Projects.

Kalbar PP, Karmakar S and Asolekar SR. (2012) Selection of an appropriate wastewater treatment technology: A scenario-based multiple-attribute decision-making approach. Journal of Environmental Management 113: 158-169.

Kamami MI. (2014) Fuzzy based decision support method for selection of sustainable wastewater treatment technologies.

Karimi A, Mehrdadi N, Hashemian S, et al. (2011) Selection of wastewater treatment process based on the analytical hierarchy process and fuzzy analytical hierarchy process methods. International Journal of Environmental Science \& Technology 8: 267-280.

Kayode OF, Luethi C and Rene ER. (2018) Management Recommendations for Improving Decentralized Wastewater Treatment by the Food and Beverage Industries in Nigeria. Environments 5: 41.

Ketema AA, Dalecha T, Assefa E, et al. (2014) Water supply and sanitation system preplanning and CLARA Simplified Planning Tool Application for Arba Minch, Ethiopia. Sustainable Sanitation Practice 19: 44-52.

Koul A and John S. (2014) A Life Cycle Cost Approach for Evaluation of Sewage Treatment Plants.

Kumar A.(2016) Selection Of Cost Effective Waste Water Treatment Technology.

Lechner M, Pressl A and Langergraber G. (2014) The CLARA simplified planning tool. Sustain. Sanit. Pract 19: 29-35.

Liu C, Li S and Zhang F. (2011) The oxygen transfer efficiency and economic cost analysis of aeration system in municipal wastewater treatment plant. Energy Procedia 5: 2437-2443.

Mardani A, Jusoh A, Zavadskas EK, et al. (2015) Sustainable and renewable energy: An overview of the application of multiple criteria decision making techniques and approaches. Sustainability 7: 13947-13984.

Massoud MA, Tarhini A and Nasr JA. (2009) Decentralized approaches to wastewater treatment and management: applicability in developing countries. Journal of Environmental Management 90: 652-659.

McGhee TJ and Steel EW. (2011) Water supply and sewerage: McGraw-Hill New York.

Mehari AK, Gebremedhin S and Ayele B. (2016) Effect of Bahir Dar municipal effluents on water quality of the head of Blue Nile River. Ethiopian Journal of Environmental Studies and Management 9: 197-208. 